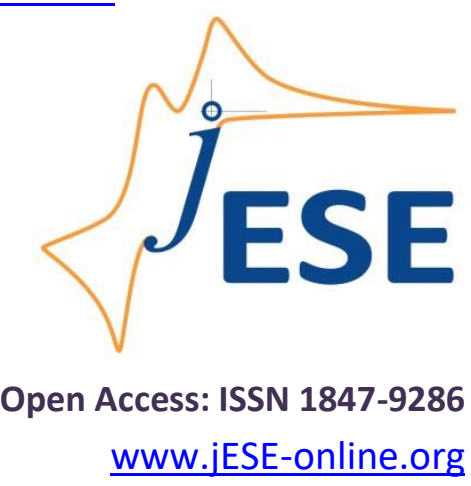

Original scientific paper

\title{
Aluminum corrosion inhibition by cefixime drug: experimental and DFT studies
}

\author{
N'guessan Y. S. Diki ${ }^{1, \bigotimes}$, Gildas K. Gbassi ${ }^{2,3}$, Augustin Ouedraogo ${ }^{1}$, Mohamed Berte ${ }^{1}$, \\ Albert Trokourey ${ }^{1}$ \\ ${ }^{1}$ Laboratoire de Chimie Physique, Université Félix Houphouët-Boigny, 22BP 582 Abidjan 22, \\ Côte d'Ivoire \\ ${ }^{2}$ Université Félix Houphouët-Boigny, UFR Sciences Pharmaceutiques et Biologiques, Département \\ de Chimie Analytique, Bromatologie, Chimie Générale et Minérale, 01 BP V 34, Abidjan, \\ Côte d'Ivoire \\ ${ }^{3}$ Laboratoire National de la Santé Publique, Service Contrôle des Aliments, 18 BP 2403, Abidjan, \\ Côte d'Ivoire
}

$₫$ Corresponding author - E-mail: dickiensil2@gmail.com

Received: May 16, 2018; Revised: June 11, 2018; Accepted: June 12, 2018

\begin{abstract}
Corrosion inhibition of aluminum in $1 \mathrm{M} \mathrm{HCl}$ by cefixime drug has been studied at 298-318 K using mass loss, Tafel polarization (at $298 \mathrm{~K}$ ) and quantum chemical methods based on density functional theory (DFT) calculations. The results showed that inhibition efficiency increases up to $90.41 \%$ with increase of the inhibitor concentration from 0.02 to $2 \mathrm{mM}$, but decreases with a rise of the solution temperature. Adsorption of cefixime molecules on the corroding aluminum surface obeys Langmuir adsorption isotherm and occurs spontaneously mostly through a physisorption process. The activation energy (Ea) as well as other thermodynamic parameters of the inhibition process are calculated and discussed. Potentiodynamic polarization data revealed that cefixime acts as mixed-type inhibitor and pointed out an agreement with mass loss results. Surface analysis is performed using scanning electron microscopy (SEM) which confirmed existence of a protective film of inhibitor molecules on the aluminum surface. In addition, global and local reactivity parameters of the studied molecule are analyzed and discussed. The computed results are found in agreement with experimental data.
\end{abstract}

Keywords

Adsorption, mass loss, Tafel polarization, SEM, global and local descriptors 


\section{Introduction}

Corrosion of metals is a major industrial, economical and safety concern that has focused many investigations and researches [1-3]. Metals generally undergo corrosion phenomenon in contact with water (and moisture in the air), acids, bases, salts, oils, aggressive metal polishes, and other solid and liquid chemicals [4]. Hydrochloric acid solutions are normally used for pickling of aluminum and electrochemical etching processes that normally lead to a substantial loss of metal due to corrosion. Due to its extensive use in industry and domestic applications, many research papers deal with aluminum corrosion. Among several methods capable to slow down aluminum corrosion, the most effective and practical [5-7] method is related to addition of organic corrosion inhibitors into metals environment.

Various organic compounds containing heteroatoms such as $\mathrm{O}, \mathrm{N}$ and $\mathrm{S}$ have already been reported as good inhibitors for aluminum corrosion in $\mathrm{HCl}$ media. It is generally admitted $[8,9]$ that organic compounds exert their inhibitory action via adsorption on a metal surface through heteroatoms and their double bonds in aromatic rings. However, the increased awareness towards the environmental pollution and control have led research groups to focus on less toxic and environmentally friendly corrosion inhibitors such as drugs. There exists a general agreement in the literature that drugs are inhibitors which compete favorably with green corrosion inhibitors and that most drugs can be synthesized from natural products. Some drugs (such as ampicillin, clotrimazole, cloxacillin, flucloxacillin, amoxicillin, etc.) have been found as good inhibitors for the corrosion of aluminum [9]. Cefixime with chemical structure shown in Scheme 1 is the commercial name of (6R, 7R)-7-[[2-(2amino-1, 3-thiazol-4-yl)-2-carboxymethyloxyimino) acetyl] amino]-3-ethenyl-8-oxo-5--thia-1-azabicyclo [4.2.0] oct-2-ene-2 carboxylic acid. It is the third generation semi synthetic cephalosporin antibiotic. Cephalosporins are derivatives of 7-aminocephalosporic acid and are closely related to penicillins in structure. The molecular formula of cefixime is $\mathrm{C}_{16} \mathrm{H}_{15} \mathrm{~N}_{5} \mathrm{O}_{7} \mathrm{~S}_{2}$ and molecular weight is $453.45 \mathrm{~g} \mathrm{~mol}^{-1}$.

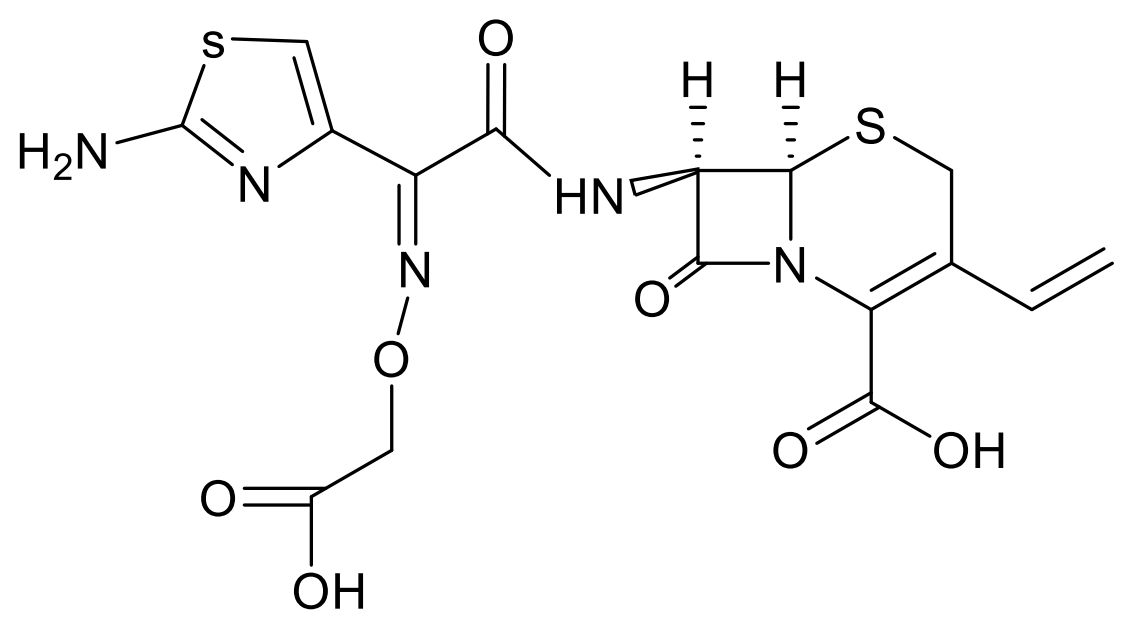

Scheme 1: Chemical structure of cefixime

A detailed literature review shows lack of data regarding the behavior of cefixime as aluminum corrosion inhibitor in $\mathrm{HCl}$ medium. In the present study, electronic properties provided by quantum chemistry calculations at DFT/B3LYP level with 6-31G (d, p) basis set of this compound are reported for the first time. Mass loss measurements, Tafel polarization and surface characterization by scanning electron microscopy were additionally reported. The inhibition mechanism has been proposed based on obtained results. 


\section{Experimental}

\section{Aluminum specimen and reagents}

\section{Aluminum specimen}

The samples of aluminum were cut from the commercial aluminum AA 1060 of purity $99.6 \%$ into the form of rods having $10 \mathrm{~mm}$ of length and $2.5 \mathrm{~mm}$ of diameter.

\section{Reagents}

Cefixime of analytical grade was acquired from Sigma-Aldrich. Analytical grade $37 \%$ hydrochloric acid solution from Sigma-Aldrich was used to prepare corrosive aqueous solutions. Acetone of purity $99.5 \%$ was also purchased from Sigma-Aldrich.

\section{Solution preparation}

The solution was prepared by dilution of $37 \% \mathrm{HCl}$ solution using double distilled water. The blank sample was $1 \mathrm{M} \mathrm{HCl}$ solution, while solutions of $1 \mathrm{M} \mathrm{HCl}$ containing inhibitor were prepared with cefixime concentrations in the range of $0.02-2 \mathrm{mM}$.

\section{Mass loss measurements}

Mass loss measurements of Al specimens were carried out in a $100 \mathrm{~mL}$ capacity glass beaker placed in a Memmert thermostat water bath. The solution volume was $50 \mathrm{~mL}$. The oxide existing on the Al samples were removed by abrading sample surfaces mechanically. The eventual rest of oxide was dissolved with acetone and Al samples were finally washed with double distillated water and dried in an oven (Memmert). For mass loss measurements, Al samples were firstly weighed accurately $\left(m_{2}\right)$ using the analytical Sartorius balance (precision: $\pm 0.1 \mathrm{mg}$ ). After that, the samples were immersed in aerated and unstirred $1 \mathrm{M} \mathrm{HCl}$ solution without or with desired concentrations of cefixime at a given temperature (precision: $\pm 0.5^{\circ} \mathrm{C}$ ). After $1 \mathrm{~h}$ of immersion, Al samples were taken out, washed again with double distilled water, dried and re-weighed accurately $\left(m_{2}\right)$. Triplicate measurements were performed in each case and the mean value of the mass loss was reported. The standard deviation of the observed mass loss was $\pm 1 \%$. Corrosion rate $W / \mathrm{mg} \mathrm{h}^{-1} \mathrm{~cm}^{-2}$, degree of surface coverage $(\theta)$ and inhibition efficiency IE, \% were calculated using following equations:

$$
\begin{aligned}
& W=\frac{m_{1}-m_{2}}{S t} \\
& \theta=\frac{W_{0}-W}{W_{0}} \\
& \mathrm{IE}, \%=\frac{W_{0}-W}{W_{0}} 100
\end{aligned}
$$

In Eqs. 1-3 $W_{0}$ and $W$ are corrosion rates without and with cefixime, $m_{1}$ and $m_{2}$ are masses before and after immersion in the corrosive aqueous solution, $S$ is the total surface area of the aluminum specimen and $t$ is immersion time.

\section{Electrochemical measurements}

Electrochemical experiments were carried out at ambient temperature (298 K) in a conventional three-electrode glass cell of $100 \mathrm{~mL}$ cell capacity. Aluminum rod served as the working electrode (WE) having the exposed surface of $0.884 \pm 0.001 \mathrm{~cm}^{2}$ and the rest being covered by a commercially available polymeric resin. A platinum electrode and a saturated calomel electrode (SCE) coupled to a fine Luggin capillary served as the counter (CE) and reference (RE) electrode, respectively. All potential values given in this study are referred to the SCE reference. Solutions were aerated, unstirred and 
prepared like these used for mass loss measurements. All measurements were performed with the Autolab PGSTAT 20 potentiostat (Ecochemie, Utrecht Netherlands) controlled by GPES 4.4 software. Origin 6.0 software was used for plotting, graphing and fitting data. Before each measurement, the Al working electrode was prepared as described for mass loss measurements and immersed in the test solution for $30 \mathrm{~min}$ to establish a steady state at the open circuit potential $\left(E_{\text {ocp }}\right)$. Tafel polarization curves were carried out from linear potential sweep at the scan rate of $1 \mathrm{mV} / \mathrm{s}$ applied from cathodic potential of $-1500 \mathrm{mV}$ to anodic potential of $+500 \mathrm{mV}$ with respect to the $E_{\text {ocp. }}$. Each experiment was repeated at least three times using always a fresh Al electrode. Only well reproducible results were reported. The inhibition efficiency (IE, \%) was calculated according to the following equation:

$$
\mathrm{IE}, \%=\frac{j_{\text {corr }}^{0}-j_{\text {corr }}^{\text {inh }}}{j_{\text {corr }}^{0}} 100
$$

where $j_{\text {corr }}^{0}$ and $j_{\text {corr }}^{\text {inh }}$ are referred to the corrosion current density in solutions without and with the inhibitor, respectively.

\section{Surface characterization}

The scanning electron microscopy (FEG SEM, SUPRA 4OVP, ZEISS, Germany) was used to study the morphology of the aluminum surface after its treatment in the presence or absence of cefixime drug for $1 \mathrm{~h}$ immersion at room temperature. Comparison was made between the bare sample and the immersed ones.

\section{Quantum calculations}

In order to explore the theoretical-experimental consistency, quantum chemical calculations were performed using Gaussian $09 \mathrm{~W}$ package [10]. The molecular structure was optimized to a minimum without symmetry restrictions using B3LYP exchange correlation functional, a combination of the Becke three parameter hybrid [11] with the correlation functional of Lee- YangParr $[12,13]$ associated to $6-31 \mathrm{G}(\mathrm{d}, \mathrm{p})$ basis set [14]. Figure 1 presents the optimized structure of cefixime.

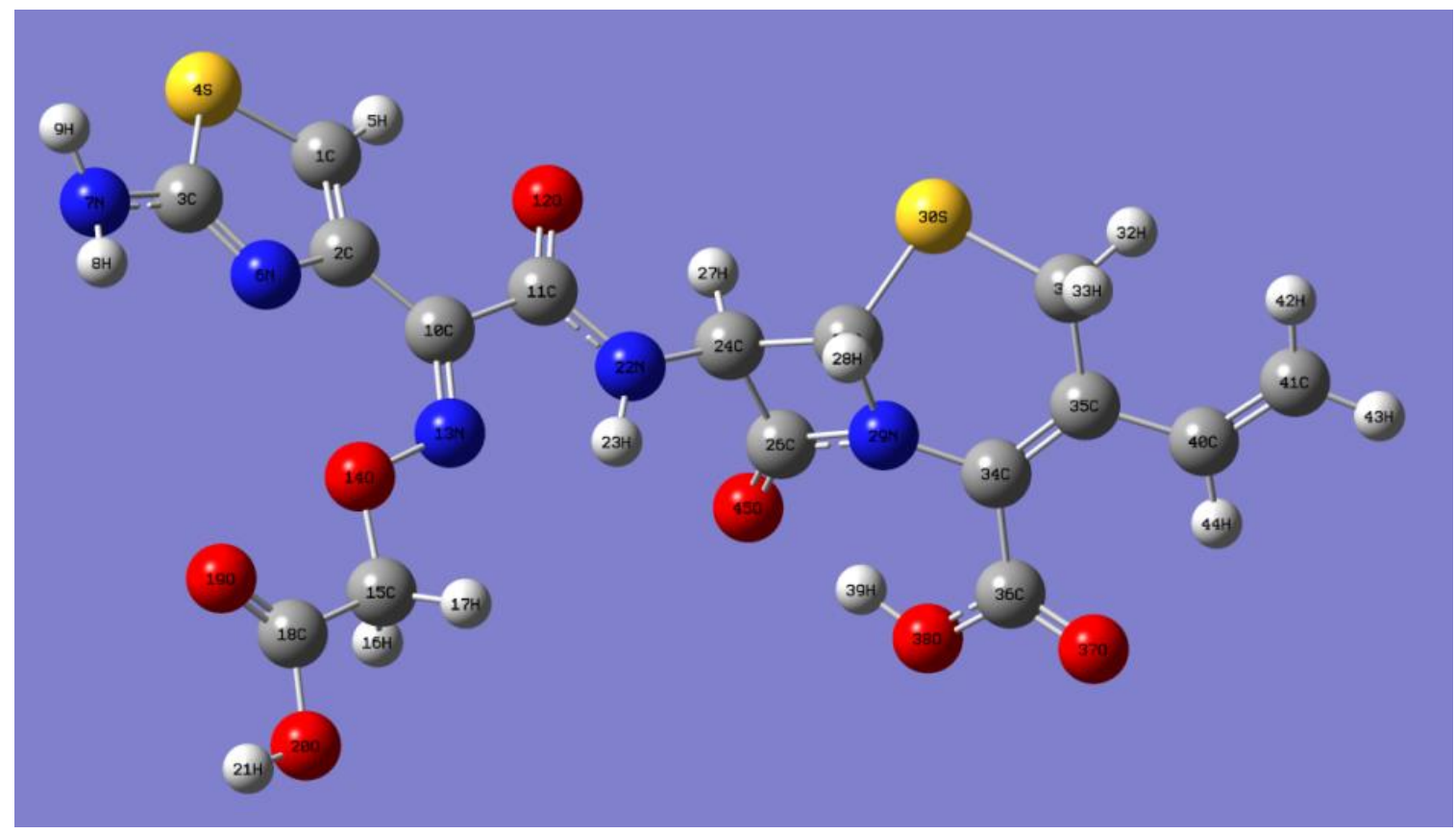

Figure 1. Optimized structure of cefixime calculated by B3LYP/6-31G $(d, p)$ 


\section{Global reactivity}

The basic relationship of density functional theory (DFT) of chemical reactivity [15] links the chemical potential $\left(\mu_{p}\right)$ with the first derivative of the total energy $(E)$ with respect to the number $(N)$ of electrons, and therefore with the negative of electronegativity $(\chi)$ :

$$
\mu_{\mathrm{p}}=\left(\frac{\partial E}{\partial N}\right)_{v(r)}=-\chi
$$

In eq. (5), $v(r)$ is the external potential of the system.

The global hardness is given by the following equation:

$$
\eta=\left(\frac{\partial^{2} E}{\partial N^{2}}\right)_{v(r)}
$$

Using the finite difference approximation and the Koopmans theorem, the global electronegativity and the global hardness can be obtained by following equations:

$$
\begin{aligned}
& \chi=\frac{1+A}{2} \approx-\frac{E_{\text {Hомо }}+E_{\text {LUMO }}}{2} \\
& \eta=\frac{1-A}{2} \approx-\frac{E_{\text {LUMO }}-E_{\text {HOMO }}}{2}=\frac{\Delta \mathrm{E}}{2}
\end{aligned}
$$

The global softness which is the reciprocal of the global hardness can be obtained as:

$$
\mathrm{S}=1 / \eta
$$

The ionization potential and the electron affinity are obtained through following equations:

$$
\begin{aligned}
& I=-E_{\text {Hомо }} \\
& A=-E_{\text {LUMO }}
\end{aligned}
$$

The electrophilicity index $\omega[16]$ is defined as:

$$
\omega=\frac{\mu_{\mathrm{p}}^{2}}{2 \eta}
$$

According to the definition, this index measures the propensity of chemical species to accept electrons. A high value of electrophilicity index describes a good electrophile while a small value of electrophilicity index describes a good nucleophile.

The fraction of electrons transferred $(\Delta N)$ is given by [17]:

$$
\Delta N=\frac{\Phi_{\mathrm{Al}}+\chi_{\mathrm{inh}}}{2\left(\eta_{\mathrm{Al}}+\eta_{\mathrm{inh}}\right)}
$$

The values of experimental work function $\Phi_{\mathrm{Al}}=4.28 \mathrm{eV}$ [18] and hardness $\eta_{\mathrm{Al}}=0$ [19] (since for bulk metallic atoms $I=A$ ) were considered to calculate $\Delta N$. This new reactivity index measures the stabilization in energy when the system acquires an additional electronic charge $\Delta N$ from the environment [20].

\section{Local reactivity}

The Fukui functions were used to analyze the local reactivity of cefixime as a corrosion inhibitor of aluminum. The condensed Fukui functions and condensed local softness are parameters which enable us to distinguish each part of the studied compound based on its chemical behavior due to different substituent functional groups. The Fukui function is defined as the derivative of the electronic density $\rho(r)$ with respect to the number $N$ of electrons: 


$$
f(r)=\left(\frac{\partial \rho(r)}{\partial N}\right)_{v(r)}
$$

The condensed Fukui functions provide information about atoms in a molecule that have a tendency to either donate (nucleophilic character) or accept (electrophilic character) an electron or a pair of electrons [21]. The nucleophilic and electrophilic Fukui function for an atom k [22] can be computed using a finite difference approximation as seen in

$f_{\mathrm{k}}{ }^{+}=q_{\mathrm{k}}(N+1)-q_{\mathrm{k}}(N)$ for nucleophilic attack

$f_{\mathrm{k}}{ }^{-}=q_{\mathrm{k}}(N)-q_{\mathrm{k}}(N-1)$ for electrophilic attack

where $q_{\mathrm{k}}(N+1), q_{\mathrm{k}}(N)$ and $q_{\mathrm{k}}(N-1)$ are the charges of the atoms on the systems with $(N+1), N$ and $N$-1 electrons respectively.

It has been reported recently [23] that a new descriptor has been introduced $[24,25]$ which allows the determination of individual sites within the molecule with particular behaviors. A mathematical analysis reveals that dual descriptor is a more accurate tool than nucleophilic and electrophilic Fukui functions [26]. This descriptor is defined as:

$$
f(r)=\left(\frac{\partial f(r)}{\partial N}\right)_{v(r)}
$$

The condensed form [24] of the dual descriptor is given as:

$\Delta f_{\mathrm{k}}(r)=f_{\mathrm{k}}{ }^{+}-f_{\mathrm{k}}{ }^{-}$

When $\Delta f_{\mathrm{k}}(r)>0$, the process is driven by a nucleophilic attack and atom $k$ acts as an electrophile; conversely, when, $\Delta f_{\mathrm{k}}(r)<0$ the process is driven by an electrophilic attack on atom $k$ acts as a nucleophile. The dual descriptor $\Delta f_{\mathrm{k}}(r)$ is defined within the range $\{-1,1\}$, what really facilitates interpretation [26].

\section{Results and discussion}

\section{Mass loss measurements}

Effect of temperature and concentration on corrosion rate

Corrosion rates of aluminum without and with addition of cefixime in $1 \mathrm{M} \mathrm{HCl}$ at different temperatures are shown in Figure 2. The curves showed that corrosion rate of aluminum in the studied medium increases with increasing temperature, but this rise becomes moderate for higher concentrations of cefixime.

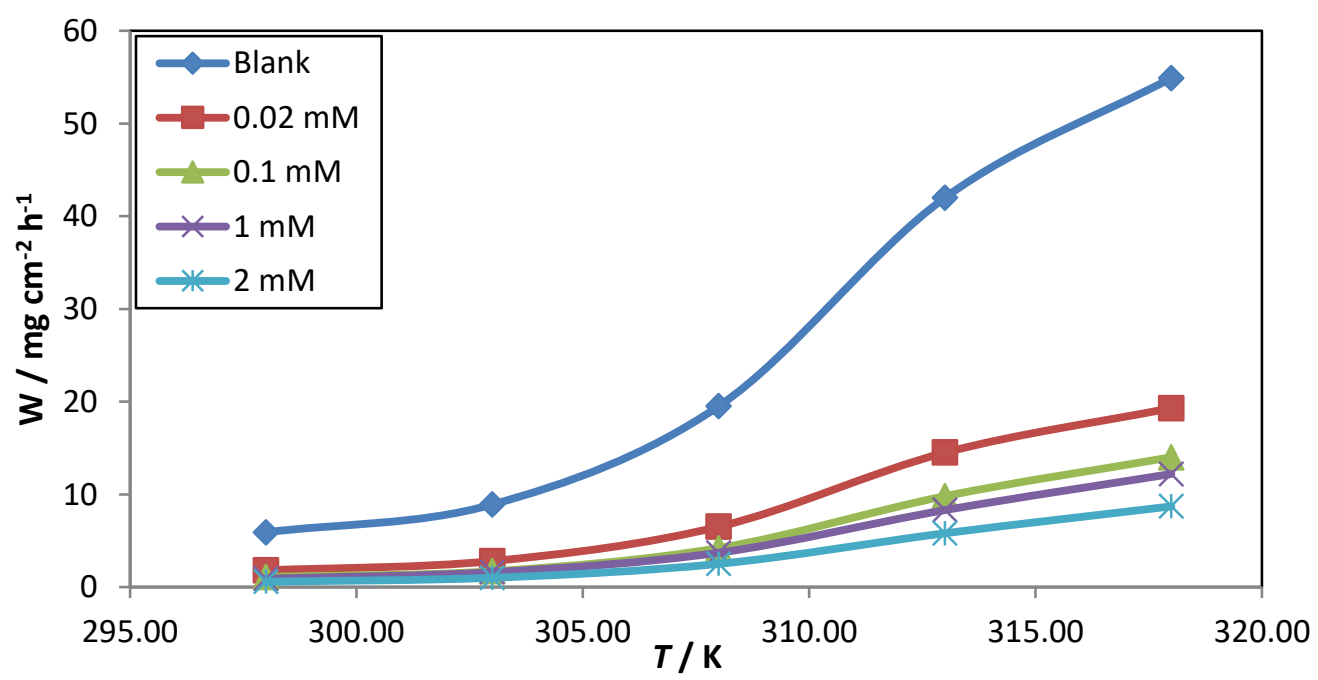

Figure 2. Evolution of corrosion rate of Al with temperature for different concentrations of cefixime in $1 \mathrm{M} \mathrm{HCl}$ 
The evolution of the corrosion rate for each concentration of cefixime highlights significant decrease of corrosion rate upon addition of the studied molecule to the acidic solution, revealing thus the effectiveness of the molecule as a corrosion inhibitor for aluminum in $1 \mathrm{M} \mathrm{HCl}$. A plausible explanation is that increase of inhibitor concentration reduces the exposed aluminum surface to the corrosive environment by the increased number of adsorbed molecules which hinder direct acid attack on the metal surface. As seen in Figure 3, the inhibition efficiency decreases as the temperature increases for the given cefixime concentration range. For the temperature range studied, however, inhibition efficiency (IE) increases with increase of the inhibitor concentration, until a value of $90.41 \%$ is attained for the concentration of $2 \mathrm{mM}$ at $298 \mathrm{~K}$.

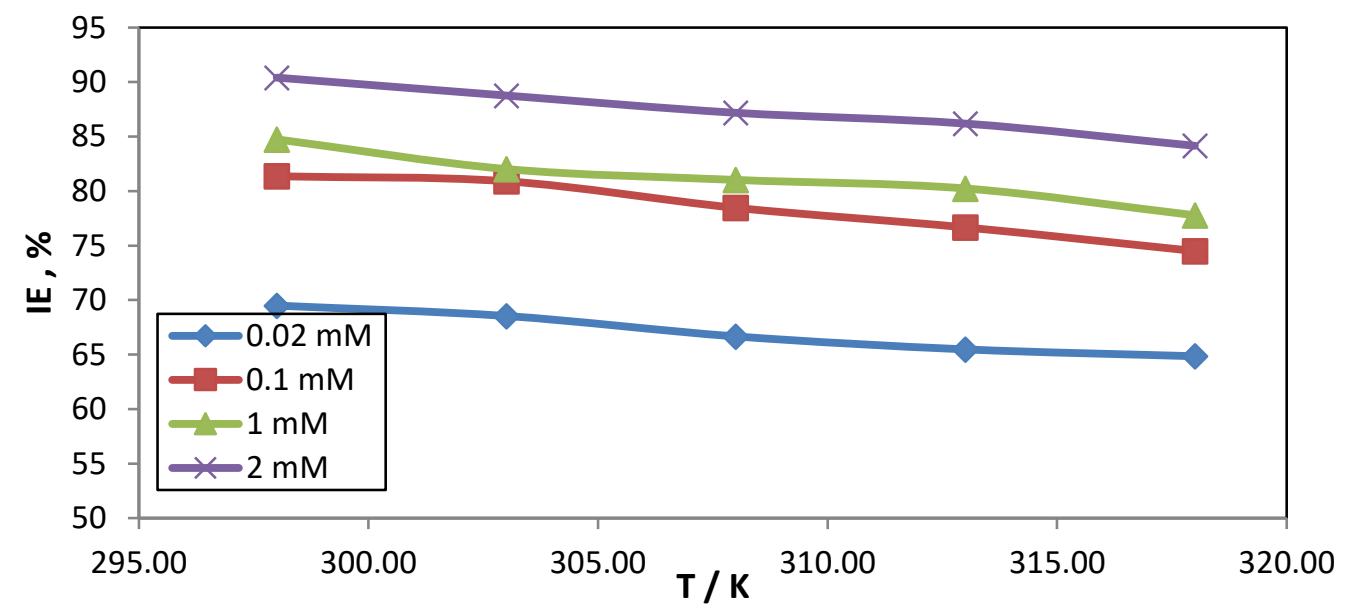

Figure 3. Inhibition efficiency vs. temperature for different concentrations of cefixime in $1 \mathrm{M} \mathrm{HCl}$

According to the literature [28], a decrease of inhibition efficiency with temperature increase indicates a physisorption of inhibitor on the corroding metal surface. Decrease of inhibition efficiency with temperature growth can also be attributed to increased solubility of the protective film and/or any reaction product precipitated on the surface of the metal [29]. As a result, the metal surface becomes more accessible to corrosive attack.

\section{Adsorption isotherms}

The basic information on the interaction between inhibitor and aluminum surface can be provided by the adsorption isotherm. Adsorption isotherms tested in this work were the models of Langmuir, Temkin, Freundlich, El-Awady and Flory Huggins. By fitting $c_{\text {inh }} / \theta$ versus inhibitor concentration curves shown in Figure 4, the best adsorption isotherm obtained graphically was the Langmuir adsorption isotherm.

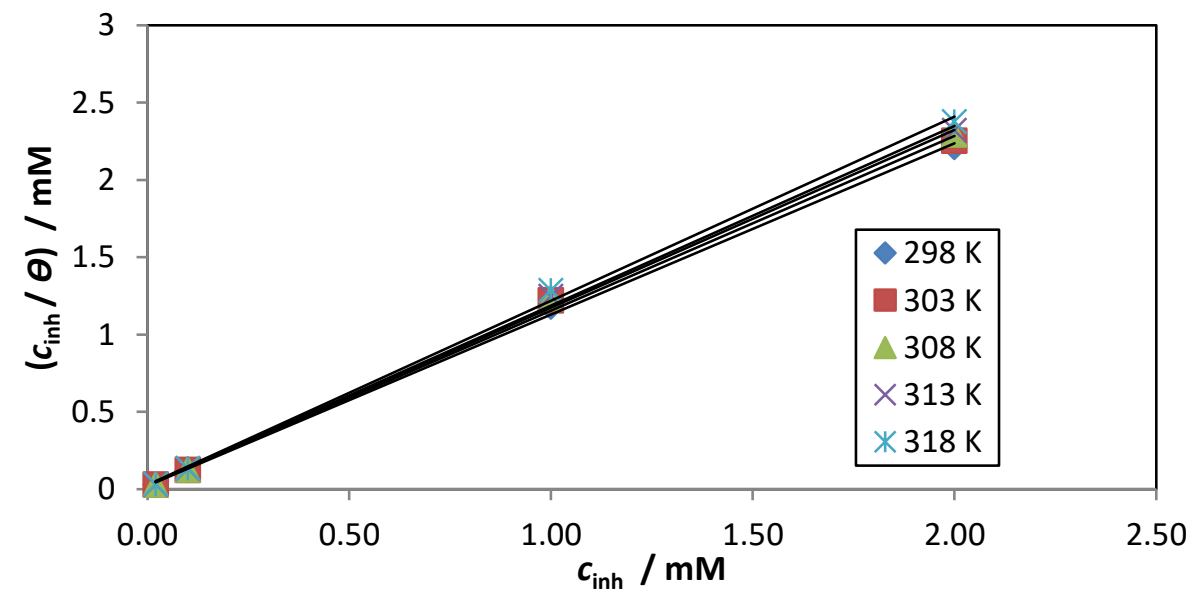

Figure 4. Langmuir adsorption isotherm for cefixime on $\mathrm{Al}$ in $1 \mathrm{M} \mathrm{HCl}$ at different temperatures 
Strong correlation $\left(R^{2}>0.998\right)$ and slopes of straight lines close to unity were obtained after fitting the Langmuir adsorption isotherm at different temperatures. Regression parameters are presented in Table 1.

Table 1. Regression parameters of Langmuir isotherm

\begin{tabular}{cccc}
\hline$T / K$ & $R^{2}$ & Slope & Intercept \\
\hline 298 & 0.9989 & 1.1072 & 0.0224 \\
\hline 303 & 0.9983 & 1.1296 & 0.0252 \\
\hline 308 & 0.9986 & 1.1491 & 0.0252 \\
\hline 313 & 0.9986 & 1.1616 & 0.0259 \\
\hline 318 & 0.9983 & 1.1905 & 0.0283 \\
\hline
\end{tabular}

This model assumes that:

- The metal surface contains a fixed number of adsorption sites and each site holds one adsorbate.

- The adsorption free energy is the same for all sites and is independent of coverage $(\theta)$.

- The adsorbates [30] do not interact with one another, i.e. there is no effect of lateral interaction of the adsorbates on the adsorption free energy.

Thermodynamic adsorption parameters

Langmuir adsorption isotherm is described by the following equation:

$\frac{c_{\text {inh }}}{\theta}=\frac{1}{K_{\text {ads }}}+c_{\text {inh }}$

In eq. (19), $c_{\text {inh }}$ is cefixime concentration, $K_{\text {ads }}$ is the equilibrium constant of the adsorption process and $\theta$ is degree of surface coverage. $K_{\text {ads }}$ is related to the free energy of adsorption $\left(\Delta G^{0}\right.$ ads $)$ by [31]:

$\Delta G^{0}$ ads $=R T \ln \left(55.5 K_{\text {ads }}\right)$

In the above equation, 55.5 is concentration of water in $\mathrm{mol} \mathrm{L}^{-1}, T$ is absolute temperature while $R$ is universal gas constant. The values of $\Delta G$ and other thermodynamic functions are summarized in Table 2.

Table 2: Adsorption thermodynamic functions

\begin{tabular}{|c|c|c|c|c|}
\hline$T / \mathrm{K}$ & $K_{\text {ads }} / \mathrm{M}^{-1}$ & $\Delta G_{\text {ads }}^{0} / \mathrm{kJ} \mathrm{mol}^{-1}$ & $\Delta H_{\text {ads }}^{0} / \mathrm{kJ} \mathrm{mol}^{-1}$ & $\Delta S^{0}{ }_{\text {ads }} / \mathrm{mol}^{-1} \mathrm{~K}^{-1}$ \\
\hline 298 & 44642.86 & -36.46 & \multirow{5}{*}{-7.7923} & \multirow{5}{*}{96.00} \\
\hline 303 & 39682.54 & -36.77 & & \\
\hline 308 & 39682.54 & -37.38 & & \\
\hline 313 & 38610.04 & -37.92 & & \\
\hline 318 & 35335.69 & -38.29 & & \\
\hline
\end{tabular}

Negative values of $\Delta G^{0}$ ads indicate a spontaneous adsorption process and stability of the adsorbed layer [32] on the aluminum surface. It has usually been recognized [31,33] that values of $\Delta G^{0}$ ads around $-40 \mathrm{~kJ} \mathrm{~mol}^{-1}$ or more negative are associated with chemisorption while these of $-20 \mathrm{~kJ} \mathrm{~mol}^{-1}$ or less negative indicate physisorption. The values displayed in Table 2 suggest both, chemisorption and physisorption. The standard adsorption enthalpy change $\left(\Delta H^{0}\right.$ ads $)$ and the standard adsorption entropy change $\left(\Delta S^{0}\right.$ ads $)$ are correlated with the standard Gibbs free energy $\Delta G^{0}$ ads by the following equation:

$\Delta G^{0}{ }_{\text {ads }}=\Delta H^{0}$ ads $-T \Delta S^{0}$ ads

According to eq. (21), thermodynamic adsorption parameters $\Delta H^{0}$ ads and $-\Delta S^{0}$ ads can be determined as the intercept and slope of the straight line obtained by plotting $\Delta G^{0}$ ads versus $T$ (Figure 5). 
Negative intercept value ( $\Delta H^{0}$ ads) observed in Figure 5 suggests an exothermic process. The literature [34] revealed that an exothermic process is characteristic for either physisorption or chemisorption. Therefore, this result confirms that the process of adsorption is both physisorption and chemisorption. The change in adsorption entropy $\left(\Delta S^{0}\right.$ ads $)$ is positive, meaning that disorder increased during the adsorption process. This situation can be explained by desorption of water molecules replaced by the inhibitor.

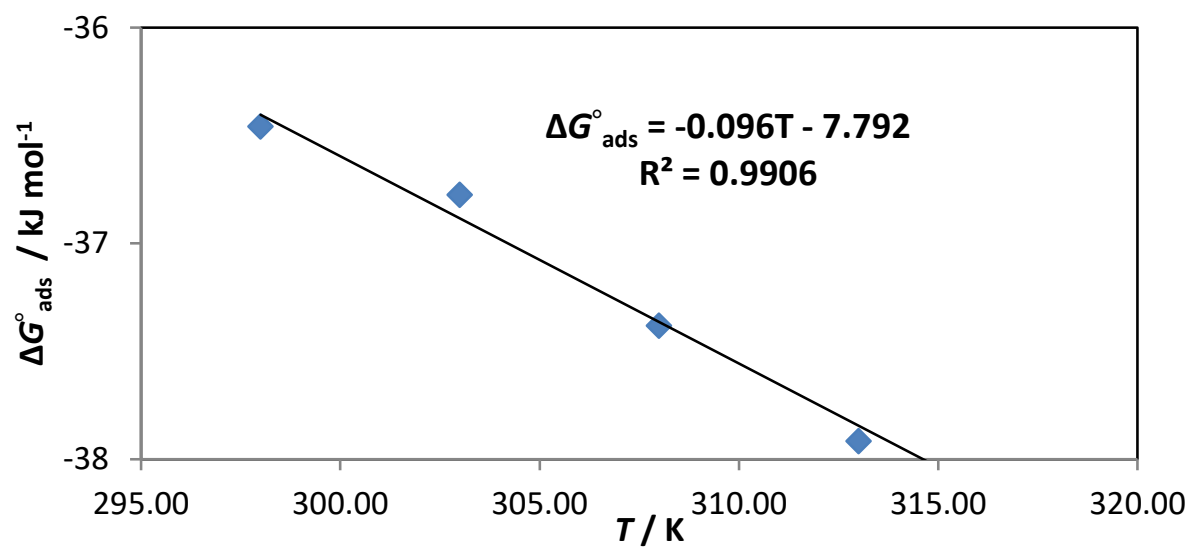

Figure 5. $\Delta \mathrm{G}^{0}$ ads vs.T for adsorption of cefixime on $\mathrm{Al}$ in $1 \mathrm{M} \mathrm{HCl}$.

\section{Effect of temperature and thermodynamic activation parameters}

Activation parameters are of great importance in any study of the corrosion inhibition mechanism. The kinetics functions for dissolution of Al without and with various concentrations of cefixime are obtained [35] by applying the Arrhenius and transition state equations:

$$
\begin{aligned}
& \log W=\log k-\frac{E_{\mathrm{a}}}{2.303 R T} \\
& \log \frac{W}{T}=\left(\log \frac{R}{N h}+\frac{\Delta S_{\mathrm{a}}^{*}}{2.303 R}\right)-\frac{\Delta H_{\mathrm{a}}^{*}}{2.303 R T}
\end{aligned}
$$

In these equations, $E_{\mathrm{a}}$ is the apparent activation energy, $k$ is the Arrhenius pre-exponential factor, $h$ is the Planck's constant, $N$ is the Avogadro number, $\Delta S^{*}{ }_{a}$ is the change in activation entropy and $\Delta H^{*}{ }_{a}$ is the change in activation enthalpy.

Plots $\log W$ and $\log W / T$ versus $1 / T$ are shown in Figures 6 and 7, respectively.

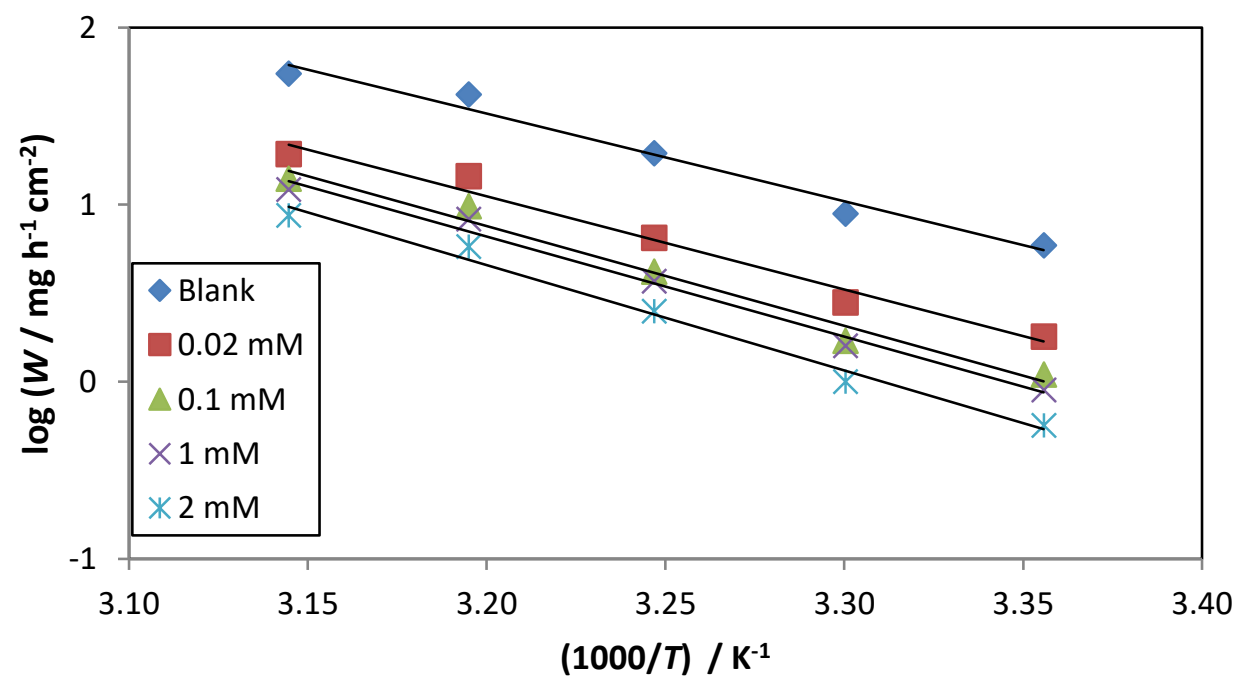

Figure 6. Arrhenius plots for Al corrosion in $1 \mathrm{M} \mathrm{HCl}$ without and with different concentrations of cefixime 


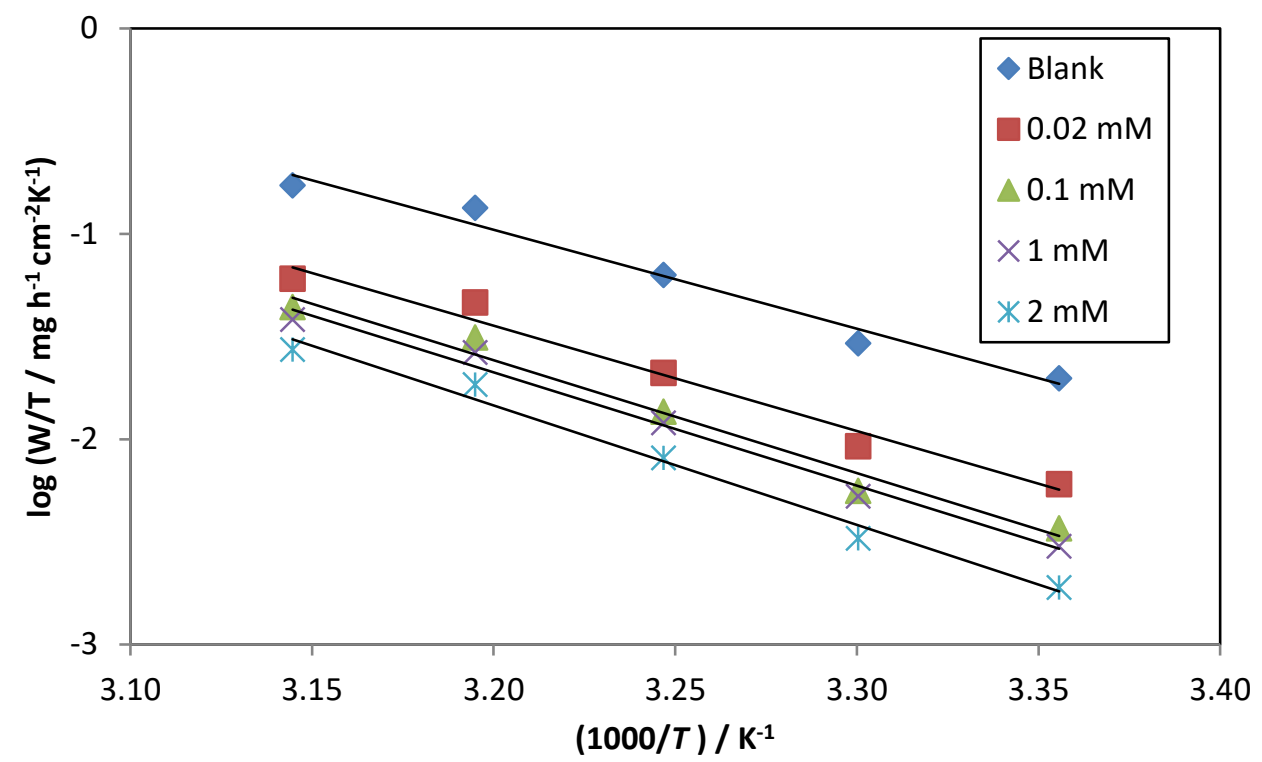

Figure 7. Transition state plots for Al corrosion in $1 \mathrm{M} \mathrm{HCl}$ with or without different concentrations of cefixime

As expected from eqs. (22) and (23), dependences presented in Figures 6 and 7 showed excellent linearity in either absence or presence of cefixime. The intercepts of lines in Figure 6 allowed calculations of values of the pre-exponential factor $(k)$, while slopes $-E_{\mathrm{a}} / 2.303 R$ facilitate determination of the activation energy $\left(E_{\mathrm{a}}\right)$ in the absence and presence of the inhibitor, respectively. The straight lines obtained by plotting log $W / T$ versus $1 / T$ shown in Figure 7 have slopes equal to $-\Delta H^{*}{ }_{a} / 2.303 R$ and intercepts equal to $\log (\mathrm{R} / \mathrm{Nh})+\Delta S^{*}{ }_{a} / 2.303 R$. The calculated values of $E_{\mathrm{a}}, \Delta H^{*}$ and $\Delta S^{*}$ are displayed in Table 3.

Table 3. Activation parameters for Al corrosion without and with cefixime in $1 \mathrm{M} \mathrm{HCl}$

\begin{tabular}{cccc}
\hline System & $E_{\mathrm{a}} / \mathrm{kJ} \mathrm{mol}^{-1}$ & $\Delta H^{*}{ }_{a} / \mathrm{kJ} \mathrm{mol}^{-1}$ & $\Delta S^{*}{ }_{a} / \mathrm{J} \mathrm{mol}^{-1} \mathrm{~K}^{-1}$ \\
\hline Blank & 94.77 & 92.09 & 78.73 \\
\hline $0.02 \mathrm{mM}$ & 100.71 & 98.02 & 88.79 \\
\hline $0.1 \mathrm{mM}$ & 107.76 & 105.07 & 108.13 \\
\hline $1 \mathrm{mM}$ & 108.14 & 105.44 & 108.19 \\
\hline $2 \mathrm{mM}$ & 113.85 & 111.15 & 123.38 \\
\hline
\end{tabular}

According to values displayed in Table 3, it seems that $E_{\mathrm{a}}$ and $\Delta H^{*}{ }_{a}$ varied in the same manner, what is probably due to the thermodynamic relation existing between them $\left(\Delta H_{a}^{*}=E_{\mathrm{a}}-R T\right)$. Higher values of $E_{\mathrm{a}}$ in the presence, compared to the $E_{\mathrm{a}}$ in the absence of inhibitor in the hydrochloric acid solution indicates that presence of inhibitor induces the energy barrier for the corrosion reaction which leads to the decreasing of rate of Al corrosion [32]. Furthermore, inhibition efficiencies decrease with the increase in temperature. According to findings of several authors [36-39], these pointed out to a predominance of a physisorption process. The value of $\Delta S^{*}{ }_{a}$ is higher for solutions containing the inhibitor than for the blank solution. This might be a result of adsorption of cefixime molecules from the acid solution that could be regarded as quasi-substitution between cefixime in the aqueous phase and water molecules on the aluminum surface. In such conditions, adsorption of inhibitor molecules was accompanied with desorption of water molecules from the aluminum surface. Thus increase in the entropy of activation is attributed to the solvent $\left(\mathrm{H}_{2} \mathrm{O}\right)$ entropy [40]. 


\section{Potentiodynamic polarization}

Figure 8 shows potentiodynamic polarization curves for $\mathrm{Al}$ in $1 \mathrm{M} \mathrm{HCl}$ solution without and with presence of various concentrations of cefixime.

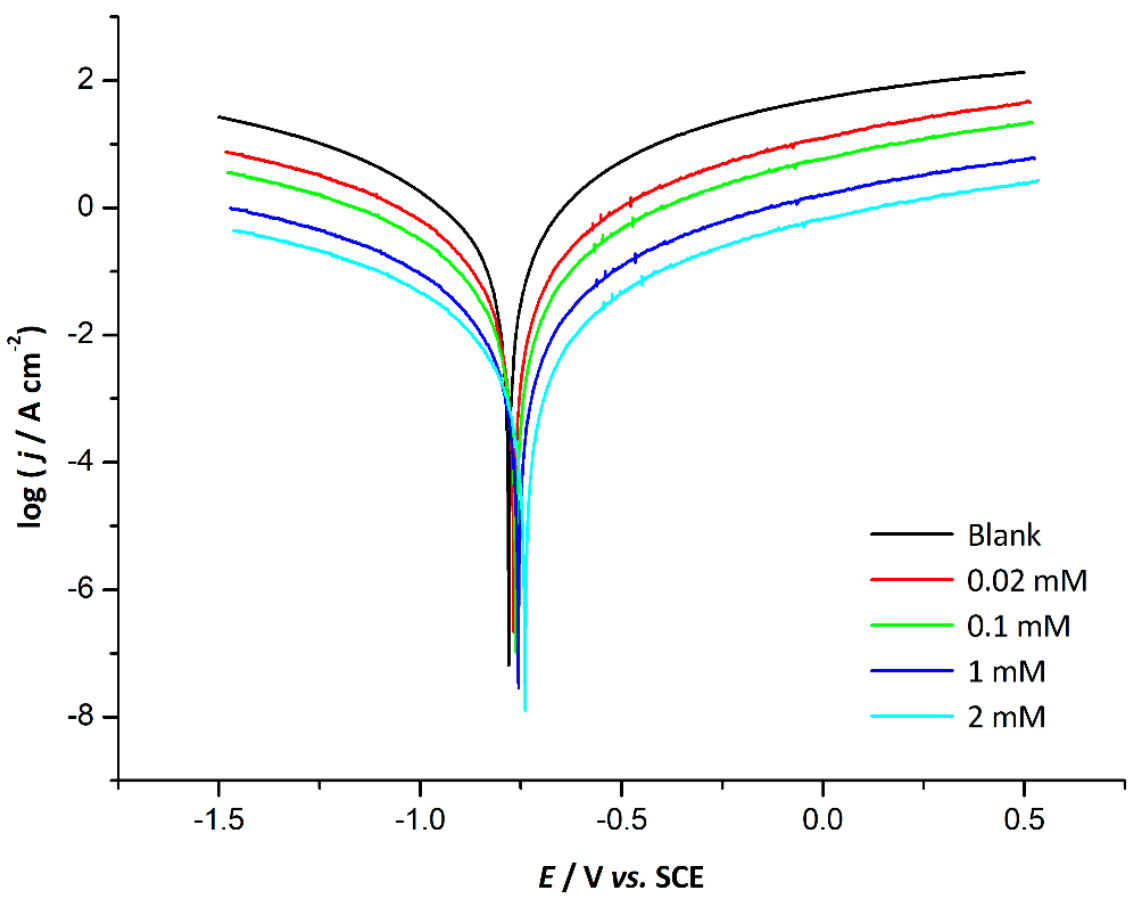

Figure 8. Potentiodynamic polarization curves for $\mathrm{Al}$ in $1 \mathrm{M} \mathrm{HCl}$ without and with different concentrations of cefixime

One can see from Figure 8 that presence of cefixime in $1 \mathrm{M} \mathrm{HCl}$ reduced both, anodic and cathodic current density values, indicating approximately equal inhibiting action on cathodic and anodic processes [41]. This result revealed that addition of cefixime reduces anodic dissolution of the metal and also retards the hydrogen evolution reaction [42]. The decrease in current densities when the inhibitor concentration rises may be due to adsorption of the inhibitor on the metal/acid interface $[43,44]$. The linear Tafel segments of anodic and cathodic curves were extrapolated to the corrosion potential in order to obtain corrosion current densities $\left(j_{\text {corr }}\right)$ which are reported in Table 4 . The computed values of other electrochemical kinetic parameters, i.e., corrosion potential $\left(E_{\mathrm{corr}}\right)$, cathodic Tafel slope $\left(-b_{c}\right)$, anodic Tafel slope $\left(b_{a}\right)$ and inhibition efficiency (IE) are also presented in Table 4.

Table 4: Potentiodynamic polarization data for corrosion of $\mathrm{Al}$ in $1 \mathrm{M} \mathrm{HCl}$ solutions without and with various concentrations of cefixime at $298 \mathrm{~K}$

\begin{tabular}{cccccc}
\hline$c_{\text {inh }} / \mathrm{mM}$ & $E_{\text {corr }} / \mathrm{mV} v s . \mathrm{SCE}$ & $j_{\text {corr }} / \mu \mathrm{A} \mathrm{cm}$ & $b_{\mathrm{a}} / \mathrm{mV} \mathrm{dec}^{-1}$ & $-b_{\mathrm{c}} / \mathrm{mV} \mathrm{dec}^{-1}$ & $\mathrm{IE} / \%$ \\
\hline 0 (Blank) & -783.53 & 201.06 & 154.85 & 115.32 & - \\
\hline 0.02 & -781.11 & 65.87 & 108.92 & 106.60 & 67.24 \\
\hline 0.1 & -777.90 & 46.42 & 102.53 & 108.60 & 76.91 \\
\hline 1 & -772.56 & 36.88 & 102.50 & 113.50 & 81.66 \\
\hline 2 & -769.75 & 23.75 & 121.75 & 108.93 & 88.19 \\
\hline
\end{tabular}

According to data in Table 4, addition of cefixime to $1 \mathrm{M} \mathrm{HCl}$ solution produced only slight changes in the values of cathodic Tafel slope $\left(-b_{c}\right)$, suggesting that adsorbed molecules do not affect the mechanism of hydrogen evolution [45] occurring mainly through the charge transfer mechanism [46]. Similarly, the value of anodic Tafel slope $\left(b_{a}\right)$ is lower in the presence of cefixime than in blank 
solution, but stays approximately constant at all concentrations of inhibitor. This suggest that the mechanism of metal dissolution (anodic) as well as the hydrogen evolution reaction (cathodic) are almost unaffected by the inhibitor $[47,48]$. The literature data [49-51] highlighted that when corrosion potential ( $E_{\text {corr }}$ ) is higher than $\pm 85 \mathrm{mV}$ with respect to $E_{\text {corr }}$ of the blank, the inhibitor can be considered distinctively as either cathodic or anodic. In our study, the maximum displacement of $E_{\text {corr }}$ is $13.78 \mathrm{mV}$ which is much less than $\pm 85 \mathrm{mV}$, suggesting that cefixime is a mixed-type inhibitor. This result is similar to the findings of other authors [52,53] who studied the same compound as a corrosion inhibitor for carbon steel and mild steel in acidic media. Maximal inhibition of $88.19 \%$ is obtained at the concentration of $2 \mathrm{mM}$, what is in good agreement with mass loss measurements ( IE $=90.41 \%$ at $298 \mathrm{~K}$ for $2 \mathrm{mM}$ ) discussed above.

\section{Surface studies}

In order to characterize features of Al surface in contact with chloride acid solution in the absence and presence of the studied inhibitor, a surface analysis was carried out using the scanning electron microscope immediately after corrosion tests. SEM images of Al samples before and after immersion in $1 \mathrm{M} \mathrm{HCl}$ solution without and with the optimal concentration of cefixime inhibitor are shown in Figure 9.

It is clear from SEM images that in the solution without inhibitor, the metal surface is subjected to vigorous corrosion. Thus, severe damage, clear pits and cavities are observed on the Al surface in the absence of inhibitor (Figure 9B) when compared with the polished bare metal before immersion (Figure 9A). When cefixime is present in $\mathrm{HCl}$ solution, the surface is not directly available (Figure 9C). This confirms that the Al surface is fully covered with inhibitor molecules forming a protective inhibitor film. This result also confirms the inhibitor effect of cefixime drug on the Al corrosion.

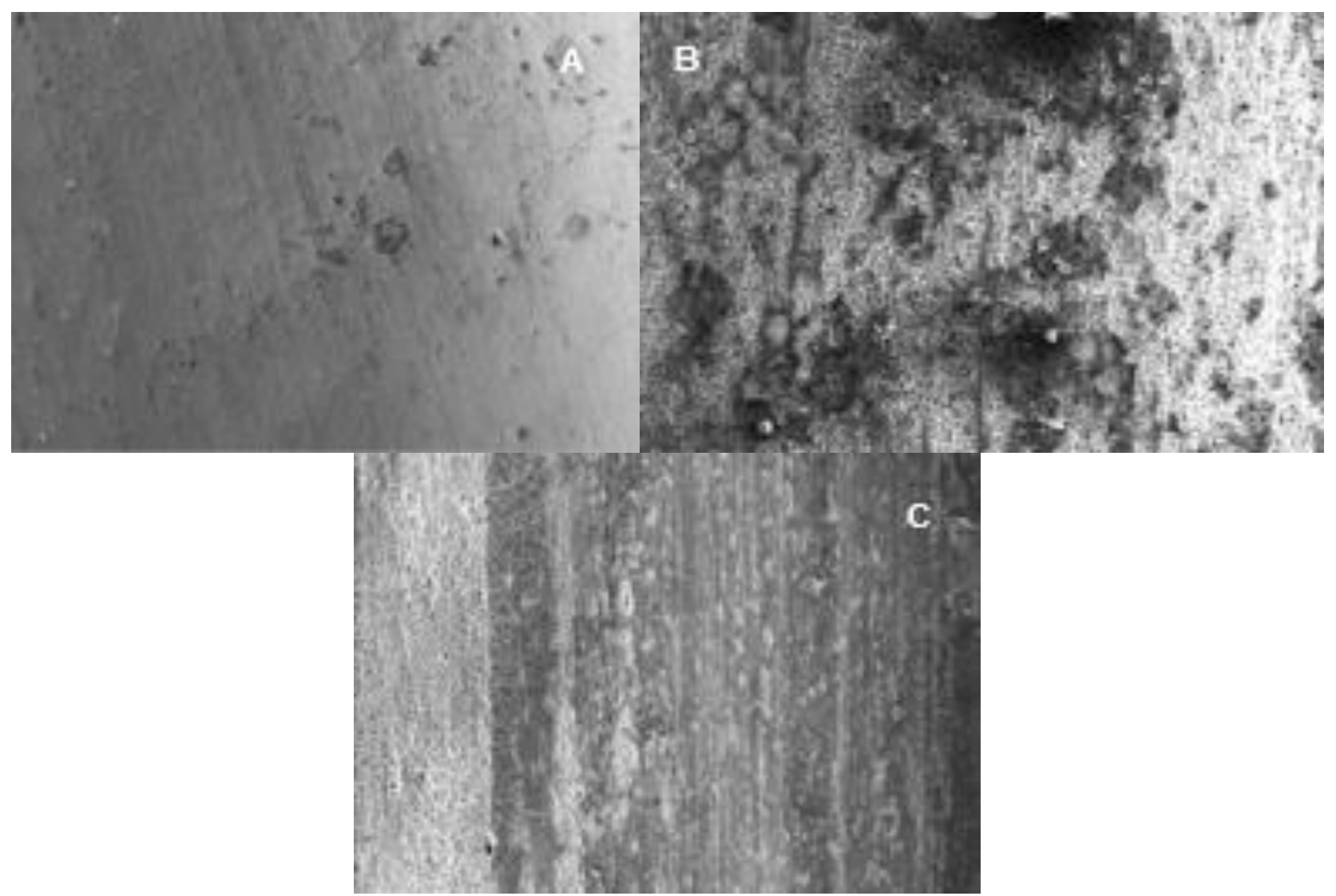

Figure 9. SEM images of Al surface: before immersion (A), after 1 h of immersion in $1 \mathrm{M} \mathrm{HCl}$ solution without inhibitor (B) and after $1 \mathrm{~h}$ of immersion in $1 \mathrm{M} \mathrm{HCl}$ solution with optimal concentration (2 $\mathrm{mM}$ ) of cefixime (C) 


\section{Quantum chemistry calculations}

\section{Global reactivity}

The values of selected quantum chemical parameters calculated for the studied cefixime molecule by using DFT methods are listed in Table 5 .

Table 5: Molecular and reactivity descriptors of cefixime.

\begin{tabular}{cc|cc}
\hline Descriptor & Value & Descriptor & Value \\
\hline$E_{\mathrm{HOMO}} / \mathrm{eV}$ & -5.8680 & $I / \mathrm{eV}$ & 5.8680 \\
$E_{\mathrm{LUMO}} / \mathrm{eV}$ & -2.0510 & $A / \mathrm{eV}$ & 2.0510 \\
$\Delta E / \mathrm{eV}$ & 3.8170 & $\mu / \mathrm{D}$ & 5.9293 \\
$\Delta N$ & 0.0840 & $\eta / \mathrm{eV}$ & 1.9085 \\
$S / \mathrm{eV}^{-1}$ & 0.5240 & $\omega$ & 4.1073 \\
$\chi / \mathrm{eV}$ & 3.9595 & $\mathrm{TE} / \mathrm{a} . \mathrm{u}$. & -2215.3776 \\
\hline
\end{tabular}

The energies [54] of the frontier orbitals $E_{\text {номо (energy of the highest occupied molecular orbital) }}$ and $E_{\text {LUMO }}$ (energy of the lowest unoccupied molecular orbital) are important in defining the reactivity of a chemical compound. $E_{\text {HOMO }}$ is often associated with the electron donating ability of a molecule, whereas $E_{\mathrm{LUM}}$ indicates the ability of a molecule to accept electrons. Therefore, a high value of $E_{\text {HOMо }}$ and a low value of $E_{\mathrm{LUMO}}$ suggest efficient adsorption process. The values obtained in the present study $\left(E_{\text {HOMO }}=-5.868 \mathrm{eV}\right.$ and $\left.E_{\mathrm{LUMO}}=-2.051 \mathrm{eV}\right)$ are comparable to that obtained for adsorption inhibitors in the literature [55]. The energy gap ( $\Delta E=E_{\text {LUMO }}-E_{\text {HOMO }}$ ) is another parameter that correlates with the reactivity of the organic molecules. Generally, lower is the energy gap; better is the electron transfer process. In this work, the low value of $\Delta E=3.817 \mathrm{eV}$ could explain high inhibition efficiency value ( $\mathrm{IE}=90.41 \%$ for $c_{\text {inh }}=2 \mathrm{mM}$ at $\left.T=298 \mathrm{~K}\right)$. HOMO and LUMO diagrams of cefixime inhibitor are presented in Figure 10.

A

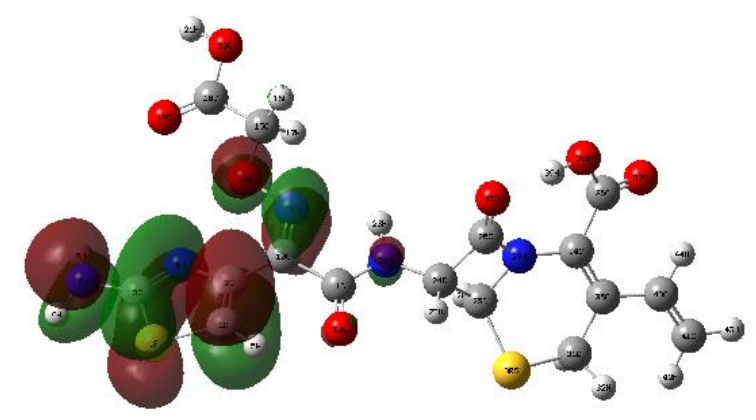

B

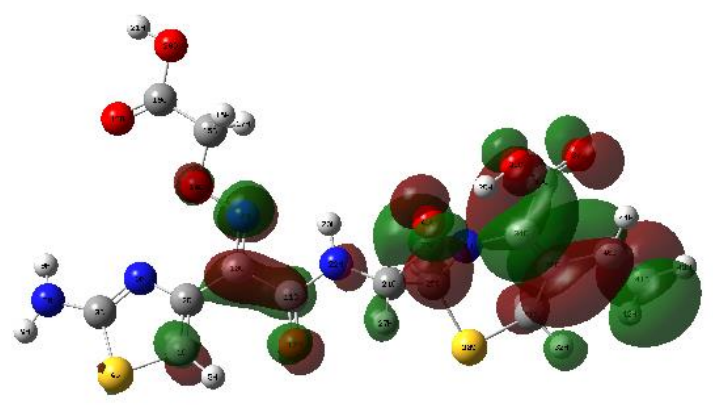

Figure 10. HOMO (A) and LUMO (B) densities of cefixime by B3LYP/6-31 $G(d, p)$

As seen in Figure 10, the density HOMO is distributed around the five-membered ring containing heteroatoms. The LUMO density is distributed almost homogeneously throughout the molecule. So, these regions are probably the active areas where transfer of electrons could be done (from the inhibitor molecule to aluminum or vice-versa).

The dipole moment $(\mu)$ is another important parameter which measures the asymmetry in molecular charge distribution [23]. It provides information about the polarity of a molecule. However, there is no consensus concerning the correlation between the dipole moment and inhibitive effectiveness [56]. According to some authors, low values of dipole moment favor inhibitor molecules accumulation on the surface thus increasing inhibition efficiency [57,58]. On the other hand, some researchers have stated that a high value of dipole moment lead to good 
inhibition efficiency of an organic molecule [59]. The ionization potential $(I)$ and the electronic affinity $(A)$ are 5.868 and $2.051 \mathrm{eV}$, respectively. This low value of $(I)$ and high value of electronic affinity $(A)$ indicate the capacity of the molecule both to donate and accept electron. The electronegativity $(\chi)$ indicates the capacity of a system to attract electrons; whereas the hardness $(\eta)$ expresses the degree of reactivity of the system (low values of hardness indicate a tendency to donate electrons). In our work the low value of the electronegativity of the studied molecule when compared to that of aluminum and the low value of hardness $(1.9085 \mathrm{eV})$ confirm the positive value of the fraction of electrons transferred $(\Delta N=0.084)$, indicating a possible motion of electrons from the inhibitor to the metal. The electrophilicity index measures the propensity of chemical species to accept electrons; a high value of electrophilicity index describes a good electrophile while a small value of electrophilicity index describes a good nucleophile. In this work the obtained value $(\omega=$ $4.1073 \mathrm{eV}$ ) shows good capacity of cefixime to accept electrons.

\section{Local reactivity}

The local reactivity can be analyzed using the atomic charges, condensed Fukui functions and the newly introduced parameter (dual descriptor) that enable to distinguish each part of the molecule based on its distinct chemical behavior due to different substituent functional groups. The Fukui function is motivated by the fact that if an electron $\delta$ is transferred to an $N$ electron molecule, it will tend to distribute and so minimize the energy of the resulting $\mathrm{N}+\delta$ electron system [60]. Thus, nucleophilic attack will occur where $f_{\mathrm{k}}{ }^{+}$value is maximum and $\Delta f_{\mathrm{k}}(r)$ is positive whereas the electrophilic attack will occur where $f_{\mathrm{k}}{ }^{-}$is maximum and $\Delta f_{\mathrm{k}}(r)$ is negative. The calculated Mulliken atomic charges, Fukui functions and dual descriptor by DFT at the B3YLP/6-31G (d, p) level are displayed in Table 6.

It is clear from shaded rows in Table 6 that (15C) with the maximum value of $f_{\mathrm{k}}{ }^{+}$and positive value of $\Delta f_{\mathrm{k}}(r)$ is the most probable nucleophilic attack site, while (35C) with the maximum value of $f_{\mathrm{k}}{ }^{-}$and negative value of $\Delta f_{\mathrm{k}}(r)$ is the most probable electrophilic attack site. These results are confirmed by the density LUMO shown in Figure 11. As surrounded in red, (15C) has no electron cloud on it whereas (35C) which is surrounded in yellow has a great electron cloud on it.

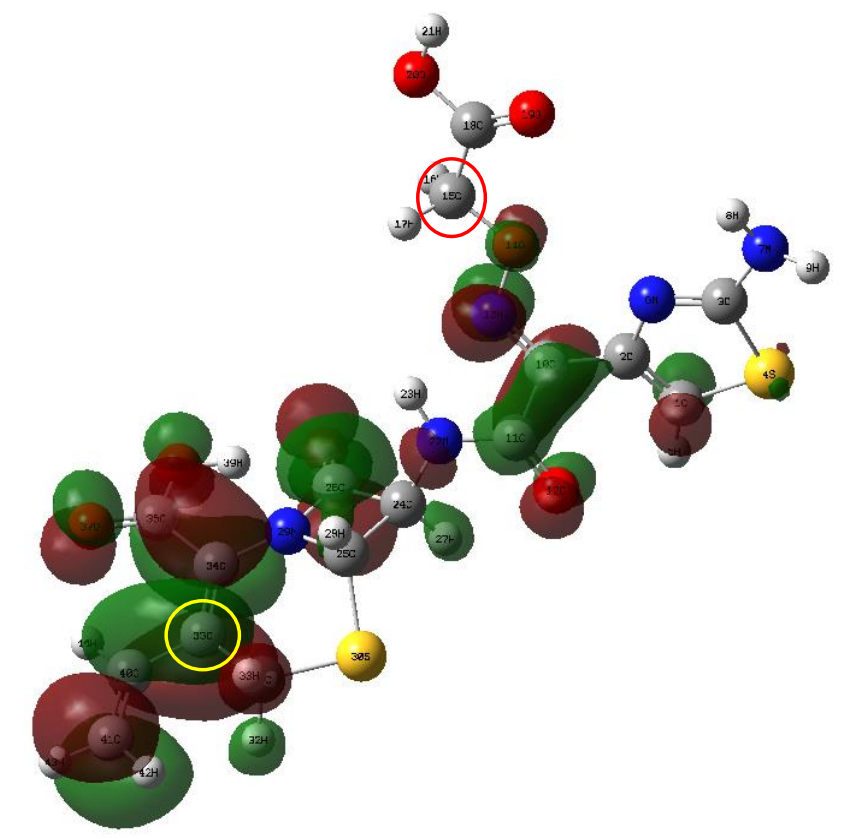

Figure 11. Electron cloud distribution on the most probable nucleophilic (15C) and electrophilic (35C) attack sites 
Table 6. Calculated Mulliken atomic charges, Fukui functions and dual descriptor by DFT B3YLP 6-31/ $G(d, p)$

\begin{tabular}{|c|c|c|c|c|c|c|}
\hline Atom & $q_{\mathrm{N}+1}$ (anion) & $q_{N}$ (neutral) & $q_{\mathrm{N}-1}$ (cation) & $f_{\mathrm{k}}^{+}$ & $f_{\mathrm{k}}^{-}$ & $\Delta f_{\mathrm{k}}(r)$ \\
\hline $1 C$ & -0.340 & -0.318 & -0.275 & -0.022 & -0.043 & 0.021 \\
\hline $2 C$ & 0.292 & 0.290 & 0.322 & 0.002 & -0.032 & 0.034 \\
\hline $3 C$ & 0.261 & 0.282 & 0.334 & -0.021 & -0.052 & 0.031 \\
\hline $4 S$ & 0.144 & 0.221 & 0.361 & -0.077 & -0.140 & 0.063 \\
\hline $6 \mathrm{~N}$ & -0.456 & -0.459 & -0.446 & 0.003 & -0.013 & 0.016 \\
\hline $7 N$ & -0.627 & -0.621 & -0.578 & -0.006 & -0.043 & 0.037 \\
\hline $10 \mathrm{C}$ & 0.215 & 0.241 & 0.245 & -0.026 & -0.004 & -0.022 \\
\hline $11 \mathrm{C}$ & 0.571 & 0.605 & 0.633 & -0.034 & -0.028 & -0.006 \\
\hline 120 & -0.576 & -0.526 & -0.522 & -0.050 & -0.004 & -0.046 \\
\hline $13 N$ & -0.350 & -0.277 & 0.230 & -0.073 & -0.507 & 0.434 \\
\hline 140 & -0.376 & -0.355 & -0.331 & -0.021 & -0.024 & 0.003 \\
\hline $15 \mathrm{C}$ & 0.077 & 0.045 & 0.016 & 0.032 & 0.029 & 0.003 \\
\hline $18 \mathrm{C}$ & 0.529 & 0.541 & 0.556 & -0.012 & -0.015 & 0.003 \\
\hline 190 & -0.454 & -0.435 & -0.436 & -0.019 & 0.001 & -0.020 \\
\hline 200 & -0.492 & -0.483 & -0.469 & -0.009 & -0.014 & 0.005 \\
\hline $22 N$ & -0.537 & -0.534 & -0.532 & -0.003 & -0.002 & -0.001 \\
\hline $24 C$ & -0.054 & -0.054 & -0.066 & 0.000 & 0.012 & -0.012 \\
\hline $25 \mathrm{C}$ & -0.035 & -0.049 & -0.062 & 0.014 & 0.013 & 0.001 \\
\hline $26 C$ & -0.560 & 0.508 & 0.604 & -1.068 & -0.096 & -0.972 \\
\hline $29 N$ & -0.528 & -0.529 & -0.522 & 0.001 & -0.007 & 0.008 \\
\hline $30 \mathrm{~S}$ & 0.087 & 0.149 & 0.191 & -0.062 & -0.042 & -0.020 \\
\hline $31 \mathrm{C}$ & -0.414 & -0.433 & -0.443 & 0.019 & 0.010 & 0.009 \\
\hline $35 \mathrm{C}$ & 0.056 & 0.165 & 0.099 & -0.109 & 0.066 & -0.175 \\
\hline $36 C$ & 0.572 & 0.591 & 0.601 & -0.019 & -0.010 & -0.009 \\
\hline 370 & -0.512 & -0.457 & -0.424 & -0.055 & -0.033 & -0.022 \\
\hline 380 & -0.556 & -0.510 & -0.487 & -0.046 & -0.023 & -0.023 \\
\hline $40 \mathrm{C}$ & -0.054 & -0.040 & -0.043 & -0.014 & 0.003 & -0.017 \\
\hline $41 C$ & -0.303 & -0.264 & -0.234 & -0.039 & -0.030 & -0.009 \\
\hline 450 & -0.541 & -0.499 & -0.464 & -0.042 & -0.035 & -0.007 \\
\hline
\end{tabular}

\section{Mechanism of inhibition}

The inhibition efficiency of cefixime against corrosion of $\mathrm{Al}$ in $1 \mathrm{M} \mathrm{HCl}$ can be explained based on adsorption sites, their charge density, molecular size and molecular structure containing heteroatoms such as nitrogen, oxygen and sulfur with lone pair electrons. In an acid medium, the studied compound cefixime (CF) could be protonated since it contains heteroatoms. Thus, CF becomes a cation, existing in equilibrium with the corresponding molecular form according to:

$$
\mathrm{CF}+\mathrm{xH}^{+} \leftrightarrow\left[\mathrm{CFH}_{\mathrm{x}}\right]^{\mathrm{x}}
$$

Due to their specific adsorption and small degree of hydratation, chloride ions $\left(\mathrm{Cl}^{-}\right.$from $\mathrm{HCl}$ are firstly adsorbed on the positively charged [61] metal surface ( $\mathrm{Al}^{3+}{ }^{3+}$ ions cover the surface of the metal) and create an excess negative charge along the metal surface towards the solution side, what leads to the adsorption of the protonated form of the inhibitor. Therefore, a protective layer due to the electrostatic interaction between the charged species from the inhibitor and the chloride ions is formed (physisorption). The positive sign of fraction of electron transferred shows that electrons can be transferred from the inhibitor species to the aluminum. The electronic configuration of Al is 
$1 \mathrm{~S}^{2} 2 \mathrm{~S}^{2} 2 \mathrm{P}^{6} 3 \mathrm{~S}^{2} 3 \mathrm{P}^{1}$. The incompletely filled $3 \mathrm{P}$ orbital of Al could bond with HOMO of cefixime while the filled $3 S$ orbital could interact with LUMO of cefixime what could explain the existence of chemisorption. So, a probable schematic mechanism sketched in Scheme 2, can be proposed. Black arrows in Scheme 2 indicate chemisorption, while the broken lines show the electrostatic interaction between chloride ions and the cationic form of the inhibitor.

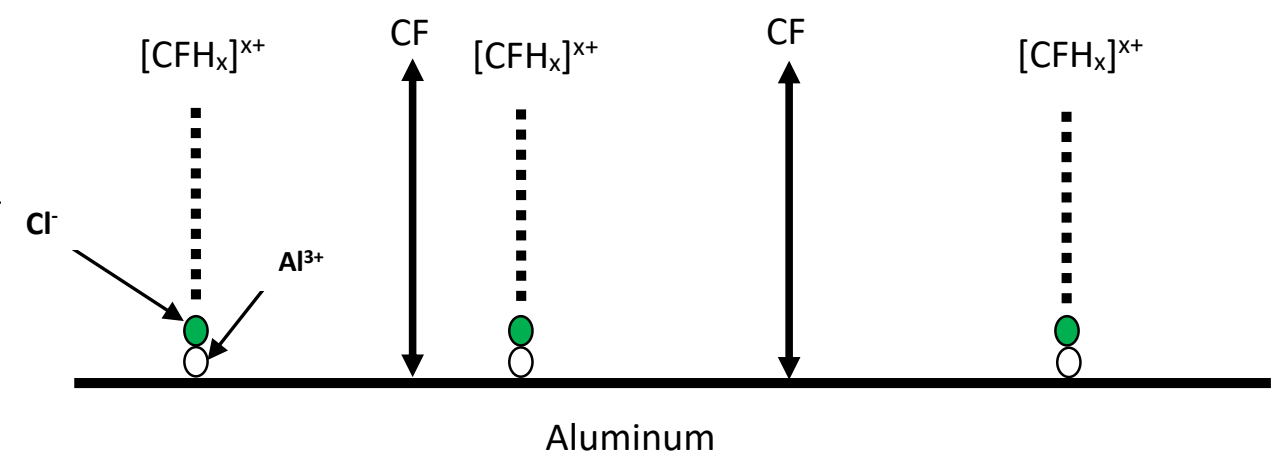

Scheme 2. Mechanism of Al corrosion inhibition by cefixime in $1 \mathrm{M} \mathrm{HCl}$

\section{Conclusions}

The following conclusions can be drawn from the present study:

- Cefixime drug is proved as an effective inhibitor for Al corrosion in $1 \mathrm{M} \mathrm{HCl}$;

- Inhibition efficiency of cefixime is temperature and concentration dependent;

- Cefixime is adsorbed on the Al surface according to the Langmuir adsorption isotherm;

- Adsorption thermodynamic functions indicate a spontaneous process of physisorption and chemisorption with a predominant physisorption;

- Tafel polarization data reveal that cefixime acts as mixed-type inhibitor;

- SEM images confirm formation of a protective layer on the All surface in presence of cefixime inhibitor;

- The quantum descriptors (global and local) confirm good inhibition efficiency of cefixime;

- Theoretical results are consistent with the experimental data.

Acknowledgments: The authors are grateful to the Laboratory of physical chemistry of Felix Houphouet-Boigny University of Cocody-Abidjan, Côte d'Ivoire.

\section{References}

1. S. Tarab, A. M. Al. Turkustani, Portugaliae Electrochimica Acta 24 (2006) 53-69.

2. N. O. Eddy, E. E. Ebenso, Pigment and Resin Technology 39 (2010) 77-83.

3. G. Karthik, M. Sundaravadivelu, Egyptian Journal of Petroleum 25 (2016) 183-191.

4. N. O. Eddy, E. E. Ebenso, International Journal of Electrochemical Science 5 (2010) 731-750.

5. O. A. Hazazi, M. Abdallah, International Journal of Electrochemical Science 8 (2013) 8138-8152.

6. M. N. El-Haddad, A. S. Fouda, Journal of Molecular Liquids 209 (2015) 480-486.

7. S. A. Umoren, I. B. Obot, N. O. Obi-Egbedi, Journal of Materials Science 44 (2009) 274-279.

8. S. M. Hassan, Y. A. Elawady, A. I. Ahmed, A. O. Baghlaf, Corrosion Science 19 (1979) 951-959.

9. M. Abdallah, Corrosion Science 46 (2004) 1981-1996.

10. M. J. Frisch, G. W. Trucks, G. E. S. H. B. Schlegel, M. A. Robb, J. R. Cheeseman, G. Scalmani, V. Barone, B. Mennucci, G. A. Petersson, H. Nakatsuji, M. Caricato, X. Li, H. P. Hratchian, A. F. Izmaylov, J. Bloino, G. Zheng, J. L. Sonnenberg, M. Hada, M. Ehara, K. Toyota, R. Fukuda, J. Hasegawa, M. Ishida, T. Nakajima, Y. Honda, O. Kitao, H. Nakai, T. Vreven, J. A. Montgomery, Jr., J. E. Peralta, F. Ogliaro, M. Bearpark, J. J. Heyd, E. Brothers, , and V. N. S. K. N. Kudin, R. Kobayashi, J. Normand, K. Raghavachari, A. Rendell, J. C. Burant, S. S. Iyengar, J. Tomasi, M. Cossi, N. Rega, J. M. Millam, M. Klene, J. E. Knox, J. 
B. Cross, V. Bakken, C. Adamo, J. Jaramillo, R. Gomperts, R. E. Stratmann, O. Yazyev, A. J. Austin, R. Cammi, C. Pomelli, J. W. Ochterski, R. L. Martin, K. Morokuma, V. G. Zakrzewski, G. A. Voth, P. Salvador, J. J. Dannenberg, S. Dapprich, A. D. Daniels, O. Farkas, J. B. Foresman, J. V. Ortiz, J. Cioslowski, D. J. Fox, Gaussian 09, Revision A.02, Gaussian, Inc., Wallingford CT, 2009.

11. A. D. Becke, Journal of Chemical Physics 98 (1993) 5648-5652.

12. C. Lee, W. Yang, R. G. Parr, Physical Review B 37 (1988) 785-789.

13. B. Miehlich, A. Savin, H. Stoll, H. Preuss, Chemical Physics Letters 157 (1989) 200-206.

14. S. G. Zhang, W. Lei, M. Z. Xia, F. Y. Wang, Journal of Molecular Structure: THEOCHEM 732 (2005) 173182.

15. R. G. Parr, R. A. Donnelly, M. Levy, W. E. Palke, Journal of Chemical Physics 68 (1978) 3801-3807.

16. R. G. Parr, L. V. Szentpaly, S. Liu, Journal of the American Chemical Society 121 (1999) 1922-1924.

17. A. Kokalj, N. Kovacevic, Chemical Physics Letters 507 (2011) 181-184.

18. H. B. Michaelson, Journal of Applied Physics 48 (1977) 4729-4734.

19. V. S. Sastri, J. R. Perumareddi, Corrosion 53 (1997) 617-622.

20. P. Udhayakala, T. V. Rajendiran, Der Pharma Chemica 7 (2015) 92-99.

21. V. Kouakou, P. M. Niamien, A. J. Yapo, A. Trokourey, Chemical Science Review and Letters 5 (2016) 131-146.

22. N. O. Eddy, S. R. Stoyanov, E. E. Ebenso, International Journal of Electrochemical Science 5 (2010) 1127-1150.

23. M. Yeo, P. M. Niamien, E. B. A. Bilé, A. Trokourey, Journal of Computational Methods in Molecular Design 7 (2017) 13-25.

24. C. Morell, A. Grand, A. Torro-Labbé, Chemical Physics Letters 425 (2006) 342-346.

25. C. Morell, A. Grand, A. Torro-Labbé, Journal of Physical Chemistry A 109 (2005) 205-212.

26. J. I. Martinez-Araya, Journal of Mathematical Chemistry 53 (2015) 451-465.

27. D. Ehouman, J. S. Akpa, P. M. Niamien, D. Sissouma, A. Trokourey, Der Pharma Chemica 8 (2016) $274-$ 286.

28. R. Saratha, R. Meenakshi, Der Pharma Chemica 2 (2010) 287-294.

29. N. Santhini, T. Jeyaraj, Journal of Chemical and Pharmaceutical Research 4 (2012) 3550-3556.

30. R. F. V. Villamil, P. Corio, J. C. Rubin, S. M. L. Agostinho, Journal of Electroanalytical Chemistry 472 (1999) 112-116.

31. H. Keles, M. Keles, I. Dehri , O. Serinday, Colloids and Surface A: Physicochemical and Engineering Aspects 320 (2008) 138-145.

32. M. R. Singh, K. Bhrara, G. Singh, Portugaliae Electrochimica Acta 26 (2008) 479-492.

33. S. Issadi, T. Douadi, A. Zouaoui, S. Chafaa, M. A. Khan, G. Bouet, Corrosion Science 53 (2011) 14841488.

34. W. Durnie, R. D. Marco, A. Jefferson, B. Kinsella, Journal of The Electrochemical Society 146 (1999) 1751-1756.

35. X. Li, S. Deng, H. Fu, G. Mu, Corrosion Science 50 (2008) 2635- 2645.

36. C. Y. Jones, G. Chen, S. Dai, P. M. Singh, Industrial and Engineering Chemistry Research 42 (2003) 4228-4233.

37. G. Back, P. M. Singh, Corrosion Science 46 (2014) 2159-2182.

38. J. R. Keiser, D. L.Singbeil, G. B.Sarma, K. A. Choudhury, P. M. Singh, C. R. Hubbard, TAPPI Journal 85 (2002) 163-167.

39. S. A. Umoren, I. B. Obot, Surface Review and Letters 15 (2008) 277-286.

40. D. K. Yadav, M. A. Quraishi, Industrial and Engineering Chemistry Research 51 (2012) 14966-14979.

41. V. M. Abbasov, H. M. A. El-Lateef, L. I. Aliyeva, E. E. Qasimov, I. T. Ismayilov, M. M. Khalaf, Egyptian Journal of Petroleum 22 (2013) 451-470.

42. A. Anejjar, R. Salghi, A. Zarrouk, O. Benali, H. Zarrok, B. Hammouti, E. E. Ebenso, Journal of Association of Arab Universities for Basic and Applied Sciences 15 (2014) 21-27.

43. I. Ahama, R. Prasad, M. A. Quraishi, Corrosion Science 52 (2010) 1472-1481.

44. N. Y. S. Diki, K. V. Bohoussou, M. G.-R. Kone, A. Ouedraogo, A. Trokourey, IOSR Journal of Applied Chemistry 11 (2018) 24-36.

45. O. Benali, L. Larabi, M.Traisnel, L. Gengembre, Y. Harek, Applied Surface Science 253 (2007) 61306139. 
46. M. Hosseini, S. F. L. Mertens, M. R. Arshadi, Corrosion Science 45 (2003) 1473-1489.

47. A. A. A. Azim, L. A. Shalaby, H. Abbas, Corrosion Science 14 (1974) 21-24.

48. M. A. Quraishi, A. Singh, V. K. Singh, D. K. Yadav, A. K. Singh, Materials Chemistry and physics 122 (2010) 114-122.

49. A. Singh, I. Ahamad, M. A. Quraishi, Arabian Journal of Chemistry 9 (2016) S1584-S1589.

50. K. R. Ansari, M. A. Quraishi, Journal of Association of Arab Universities for Basic and Applied Sciences 18 (2015) 12-18.

51. A. K. Satapathy, G. Gunasekaran, S. C. Sahoo, K. Amit, P. V. Rodrigues, Corrosion Science 51 (2009) 2848-2856.

52. I. Naqvi, A. R. Saleemi, S. Naveed, International Journal of Electrochemical Science 6 (2011) 146 - 161.

53. A. S. Fouda, A. Abdallah, M. Yousef, Chemical Science Review and Letters 3 (2014) 130-143.

54. E. E. Ebenso, T. Arslan, F. Kandemirli, I. N. Caner, I. I. Love, International Journal of Quantum Chemistry 110 (2010) 1003-1018.

55. V. Hempriya, K. Parameswari, S. Chitra, Chemical Science Review and Letters 3 (2014) 824-835.

56. I. B. Obot, N. O. Obi-Egbedi, Corrosion Science 52 (2010) 657-660.

57. N. Khalil, Electrochimica Acta 48 (2003) 2635-2640.

58. M. Şahin, G. Gece, F. Karcı, S. Bilgiç, Journal of Applied Electrochemistry 38 (2008) 809-815.

59. A. Kokalj, Electrochimica Acta 56 (2010) 745-755.

60. S. R. Stoyanov, S. Gusarov, M. S. Kuznicki, A. Kovalenko, Journal of Physical Chemistry C 112 (2008) 6794-6810.

61. H. Luo, Y. C. Guan, K. N. Han, Corrosion 54 (1998) 721-731.

(C)2018 by the authors; licensee IAPC, Zagreb, Croatia. This article is an open-access article distributed under the terms and conditions of the Creative Commons Attribution license (http://creativecommons.org/licenses/by/4.0/) 